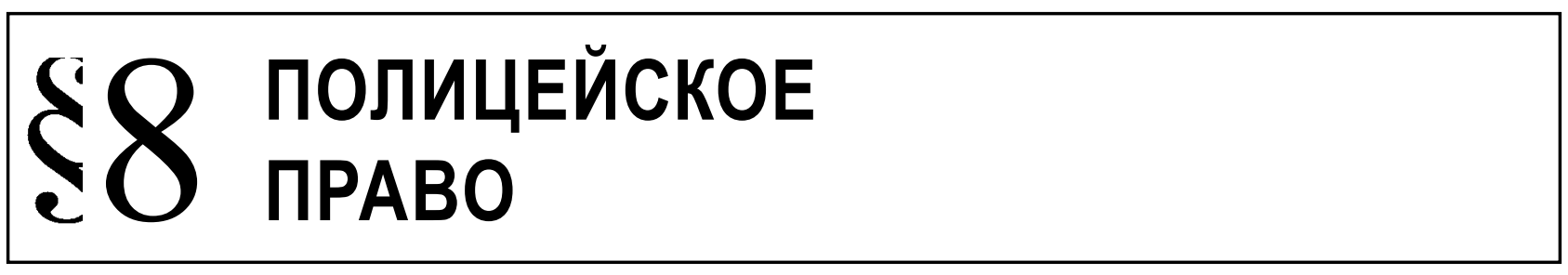

Романькова С.А.

\title{
БАЛЬНАЯ СИСТЕМА УЧЕТА ПРАВОНАРУШЕНИЙ КАК МЕХАНИЗМ СДЕРЖИВАНИЯ ВОДИТЕЛЕЙ, СИСТЕМАТИЧЕСКИ И ЗЛОСТНО НАРУШАЮЩИХ ПРАВИЛА ДОРОЖНОГО ДВИЖЕНИЯ В РОССИИ
}

\begin{abstract}
Аннотация: Предмет исследования: механизм привлечения к административной ответственности участников дорожного движения, в частности водителей транспортных средств злостно, сознательно, грубо и систематически нарушающих Правила дорожного движения Российской Федерации, стандарты и технические нормы в сфере обеспечения безопасности дорожного движения, а также иное действующее законодательство Российской Федерации в области дорожного движения в сравнении с действующим механизмом административно-правового воздействия на сознание, волю и поведение водителей транспортных средств и иных участников дорожного движения Соединенных Штатов Америки, в частности итата Миссури, в случае совершения ими систематических правонарушений в области дорожного движения, принимая во внимание законодательство и правоприменительную практику России прошлых лет. Метод, методология исследования: при разработке и написании статьи использовались статистический, формально-логический, сравнительно-правовой методы, а также метод правового моделирования. Новизна исследования, выводы: Отсутствие в России действенного механизма привлечения к административной ответственности за злостные, сознательные, грубые и систематические правонарушения, совершаемые участниками дорожного движения, требует внесения изменений в действующее законодательство в области дорожного движения, в частности возвращения бальной системы учета правонарушений. В ее основе лежит справедливая и общепринятая юридическая норма: повторность и систематичность правонарушений должна отягчать ответственность.

Ключевые слова: безопасность дорожного движения, бальная система учета, систематические правонарушения, неотвратимость ответственности, специальные технические средства, административный итраф, балл, дорожно-транспортные происшествия, Правила дорожного движения, мировой опыт.
\end{abstract}

$\Pi$ оложение дел в сфере безопасности дорожного движения приобретает черты глобального кризиса. Это вызвано и огромным ростом автомобильного парка, и пренебрежительным отношением водителей к правилам дорожного движения, и отсутствием общей правовой культуры участников дорожного движения, крайним выражением которого является злостное, систематическое нарушение водителями транспортных средств Правил дорожного движения Российской Федерации ${ }^{1}$ (далее Правил дорожного движения).

Постановление Правительства Российской Федерации от 23 октября 1993 г. № 1090 «О правилах дорожного движения (вместе с «Основными положениями по допуску транспортных средств к эксплуатации и обязанности должностных лиц по
Политика Государства в целях снижения уровня безопасности дорожного движения ужесточает административную ответственность, увеличивает санкции за правонарушения в области дорожного движения. В настоящее время ответственность за административные правонарушения в области дорожного движения предусмотрена по 37 статьям Кодекса Российской Федерации об административных правонарушения ${ }^{2}$ (далее КоАП РФ). На сегодняшний день в России, в результате принятых мер

обеспечению безопасности дорожного движения»)» // Собрание актов Президента и Правительства РФ. 1993. N 47. Ст. 4531.

2 Кодекс Российской Федерации об административных правонарушениях от 30 декабря 2001 г. № 195-Ф3 // Собрание законодательства РФ. 07.01.2002. № 1. Ст. 1. 
по ужесточению административной ответственности в области дорожного движения, минимальный размер административного штрафа составляет 500 (пятьсот) рублей, максимальный 50.000 (пятьдесят тысяч) рублей.

Для большинства граждан России размеры административных штрафов и процедуры по их уплате обременительными не являются. Из-за отсутствия действенного механизма привлечения к административной ответственности водители продолжают систематически и злостно нарушать Правила дорожного движения.

В зарубежных странах эту проблему искоренили с помощью бальной системы учета правонарушений. В Германии, США, Японии, Великобритании, Франции, Чехии, Нидерландах и др. странах бальная система учета правонарушений успешно функционирует и развивается как механизм сдерживания «дорожных рецидивистов» на протяжении многих десятилетий. Примечательной является бальная система учета правонарушений в штате Миссури. В данном штате в случае фиксации административного правонарушения работающими в автоматическом режиме специальными техническими средствами, имеющими функции фото-и киносъемки, видеозаписи или средствами фото- и киносъемки, видеозаписи и наложении на водителя транспортного средства административного штрафа одновременно дается оценка правонарушению в баллах. Количество баллов зависит от вида правонарушения в области дорожного движения. Например, можно получить 2 или 3 балла за превышение установленной скорости движения, а можно набрать 12 баллов за невыполнение обязанностей в связи с дорожнотранспортным происшествием и одновременно лишиться права управления транспортным средством. Предельные баллы, за которые водителей лишают права управления транспортным средством равны от 12 до 24. Срок, в течение которого лицо, считается подвергнутым административному наказанию, составляет от одного года до трех лет со дня окончания исполнения постановления об уплате административного штрафа. Это означает, что если водитель с момента уплаты административного штрафа продолжит совершать правонарушения, оцениваемые в сумме 12 набранных баллов в течение одного года, 18 и более баллов в течение двух лет, либо 24 и более баллов в течение трех лет, то он будет автоматически лишен водительского удостоверения на один год. Если водитель впервые наберет 8 и более баллов в течение восемнадцати месяцев, то первичный срок лишения права на управление автомобилем составит не более тридцати дней. За повторное совершение административного правонарушения, оцениваемого в сумме 8 и более баллов в течение восемнадцати месяцев, срок лишения водительских прав увеличивается еще на тридцать дней. Третье и последующие нарушения Правил дорожного движения, совершенные в эти же сроки и оцениваемые в этих же баллах, влекут за собой лишение права управления на срок не менее девяноста суток. ${ }^{3}$

По истечению срока лишения водительского удостоверения, водитель восстанавливается в правах на управление транспортным средством, причем сумма набранных баллов автоматически уменьшается на 4 балла. В последующем, если водитель в течение одного года управляет без нарушений Правил дорожного движения, оцениваемых в баллах, сумма набранных баллов автоматически уменьшается на одну треть от общего количества баллов. Если водитель не совершает правонарушений в области дорожного движения в течение двух лет, то сумма набранных баллов автоматически уменьшается наполовину, от общего количества набранных баллов, в течение трех лет - количество баллов сводится к нулю. ${ }^{4}$

Эти же правила предусмотрены для водителей совершивших правонарушения, оцениваемых в баллах, но не достигших установленного предельного балла и не лишенных прав на управление транспортным средством. Если в течение года водитель совершает правонарушение, оцениваемое в 4 балла, то ему приходит предупреждение с Министерства транспорта. ${ }^{5}$ Причем информацию о набранных баллах можно бесплатно получить путем свободного доступа в сети интернет сайта Министерства транспорта штата Миссури.

В России бальная система учета правонарушений существовала с 1993 г. по 2001 г. Однако, в связи с процветанием взяточничества и коррупции от нее отказались. Вследствие чего у участников дорожного движения утратилось чувство неотвратимости ответственности. После отмены бальной

\footnotetext{
3 Driver Guide. CHAPTER 11 THE POINT SYSTEM AND HOW IT AFFECTS YOU. SEAL OF DEPARTMENT OF REVENUE. State of MISSOURI. Revised August 2011. P. 81.

4 Driver Guide. Op. cit. P. 82.

5 Driver Guide. CHAPTER 11 THE POINT SYSTEM AND HOW IT AFFECTS YOU. SEAL OF DEPARTMENT OF REVENUE. P. 81.
} 
системы учета правонарушений, аварии в России впервые увеличились на 12 \%. Причем по количеству автомобилей на 1000 жителей мы отставали от стран Европы в 2-3 раза, а по количеству погибших в ДТП обгоняли их в 2-4 раза. ${ }^{6}$

В настоящее время по количеству погибших в дорожно-транспортных происшествиях мы обгоняем Нидерланды в 5 раз и в 2 раза Чехию, уровень автомобилизации в которой почти в 2 раза выше российского. ${ }^{7}$ При этом в $80 \%$ случаев дорожно-транспортные происшествия происходят из-за несоблюдения водителями Правил дорожного движения.

Практика воздействия на нарушителей в области дорожного движения мерами административно-правового воздействия выявила ряд существенных недостатков КоАП РФ. В частности, принимаемые законодателем меры, направлены лишь на ужесточение ответственности за управление транспортным средством водителем, находящимся в состоянии опьянения, передачу управления транспортным средством лицу, находящемуся в состоянии опьянения (ст. 12.8 КоАП РФ), невыполнения водителем транспортного средства требования о прохождении медицинского освидетельствования на состояние опьянения (ст. 12.26 КоАП РФ). Однако статистика свидетельствует, что значительная доля правонарушений, выявленных при оформлении дорожно-транспортных происшествий, приходится на другие правонарушения, совершенные водителями в области дорожного движения. Так, несоответствие скорости конкретным условиям составляет $24 \%$ от общего числа случаев, несоблюдение очередности проезда $11 \%$, выезд на полосу встречного движения 6\%. Тогда как правонарушения за управления транспортным средством в состоянии опьянения, выявленные при оформлении дорожно-транспортных происшествий, составляют лишь 5\% от общего числа правонарушений, за управление транспортным средством лицом, не имеющим права управления - $5 \%$, за управление транспортным сред-

\footnotetext{
6 Десятилетие имени Федорова: Госавтоинспекция России попытка ретроспективы. // За рулем: электрон. журн. 2003. № 3. C. 18. URL: http://www.zr.ru/archive/zr/2003/03/ diesiatilietiie-imieni-fiedorova. (дата обращения: 18.01.2014).

7 Федеральная целевая программа «Повышение безопасности дорожного движения в 20132020 годах»: утв. постановлением Правительства Российской Федерации от 3 октября 2013 г. N 864 // Собрание законодательства РФ. 2013. № 41. Ст. 5183.
}

ством водителем, лишенным права управления в состоянии опьянения - $1 \%$, отказ водителя от медицинского освидетельствования $2 \%{ }^{8}$

Для исправления сложившейся на сегодняшний день ситуации в области дорожного движения, в целях неотвратимости административных наказаний за злостные и систематические нарушения Правил дорожного движения результатом которых является гибель людей, требуется принятие решительных, даже радикальных законодательных мер. Таких как возвращение к балльной системе учета правонарушений состоятельность, которой, доказана зарубежной правоприменительной практикой в области дорожного движения. В этих целях необходимо ввести административную ответственность за систематическое нарушение Правил дорожного движения, установив предельный балл и соответствующие баллы для отдельных видов правонарушений в области дорожного движения, исходя из характера причиняемого вреда и степени тяжести последствий. Причем, начисление штрафных баллов не должно освобождать от уплаты административного штрафа. В целях недопущения любых коррупционных элементов в функционировании бальной системы необходимо исключить человеческий фактор участия при фиксации и суммировании баллов. В настоящее время в России для подразделений Госавтоинспекции закуплено 6203 комплекса видеофиксации нарушений Правил дорожного движения, работающих в автоматическом режиме, и 3352 автомобиля, оборудованных средствами контроля и выявления правонарушений. ${ }^{9}$ Это создает великолепные возможности для фиксации правонарушений в области дорожного движения и их оценке в баллах работающими в автоматическом режиме специальными техническими средствами, имеющими функции фото-и киносъемки, видеозаписи или средствами фото- и киносъемки, видеозаписи.

\footnotetext{
8 Госавтоинспекция МВД России. Состояние и тенденции ДТП с водителями, находившимися в состоянии опьянения и отказавшимися от прохождения медицинского освидетельствования на состояние опьянения за 7 месяцев 2013 года. Доли правонарушений выявленных при оформлении дорожно-транспортных происшествий URL: http://www. gibdd.ru/stat/files/dtp_ns.pdf. C. 13 Internet Explorer (дата обращения: 20.10.2014).

9 Федеральная целевая программа «Повышение безопасности дорожного движения в 20132020 годах»: утв. постановлением Правительства Российской Федерации от 3 октября 2013 г. N 864 // Собрание законодательства РФ. 2013. № 41. Ст. 5183.
} 
Примечательным является и то, что на сегодняшний момент в 74 субъектах Российской Федерации функционируют центры автоматизированной фиксации правонарушений, обеспечивающих реализацию процедур обращения административных материалов к исполнению. ${ }^{10}$ Поэтому, отнести к компетенции начальников центров автоматизированной фиксации правонарушений полномочия по учету набранных баллов и рассмотрению дел о систематических нарушениях Правил дорожного движения, предусмотренных главой 12 КоАП РФ, достигших в сумме предельного балла и зафиксированных работающими в автоматическом режиме специальными техническими средствами, было бы вполне оправданным.

Информацию о правонарушении, зафиксированном работающими в автоматическом режиме средствами видеофиксации, налагаемом штра$\phi е$ и оценке правонарушения в баллах можно бесплатно предоставлять через сеть интернет соответствующего сайта указанного центра. Более того, многие граждане России подключены к услуге «Мобильный банк» и имеют доступ в Интернет, что дает возможность бесплатного подключения и пользования услугой «Автоплатеж» за штрафы ГИБДД. С помощью данной услуги Сбербанк в отсылаемом СMC-сообщении, информирует водителя о сумме административного штрафа и возможности его оплаты посредством банковской карты, к которой подключена услуга. Посредством этой услуги возможно в отсылаемом СМС-сообщении, информировать водителя не только о сумме административного штрафа, но и набранных им баллах.

На основании изложенного, учитывая мировой опыт зарубежных стран, предлагаем внести в КоАП РФ следующие изменения:

Дополнить главу 12 новой статьей 12.38 следующего содержания:

«Статья 12.38. Систематическое нарушение правил дорожного движения, зафиксированное работающими в автоматическом режиме специальными техническими средствами, имеющими функции фото-и киносъемки, видеозаписи или средствами фото- и киносъемки, видеозаписи

10 Федеральная целевая программа «Повышение безопасности дорожного движения в 2013 - 2020 годах»: утв. постановлением Правительства Российской Федерации от 3 октября 2013 г. N 864 // Собрание законодательства РФ. 2013. № 41 . Ст. 5183.
Систематическое нарушение водителем транспортного средства Правил дорожного движения, то есть совершение им в течение трех лет нескольких административных правонарушений, предусмотренных частями 13 статьи 12.2 , частью 3 статьи 12.4 (за исключением случаев незаконного нанесения цветографической схемы легкового такси), частями 1,2 и 3.1 статьи 12.5 , статьей 12.6 , частями 26 статьи 12.9 , частями 1 и 2 статьи 12.10 , статьями $12.11,12.12,12.14$, частями 14 статьи 12.15 , частями 13 , частями 47 статьи 12.16 , статьями 12.17, 12.21 - 12.21.2, статьей 12.21 .3 (в случае фиксации административного правонарушения работающими в автоматическом режиме специальными техническими средствами, имеющими функции фото- и киносъемки, видеозаписи, или средствами фото- и киносъемки, видеозаписи), 12.23, частями 1 и 2 статьи 12.25 , статьей 12.36.1, иных правонарушений в области дорожного движения, предусмотренных главой 12 настоящего Кодекса, которые в сумме оцениваются пятнадцатью и более баллами и зафиксированы работающими в автоматическом режиме специальными техническими средствами, имеющими функции фото-и киносъемки, видеозаписи или средствами фото- и киносъемки, видеозаписи, влечет лишение права управления транспортными средствами на срок один год или наложение административного штрафа на лиц, не имеющих права управления транспортными средствами, на лиц, в отношении которых в соответствии с настоящим Кодексом не может применяться лишение права управления транспортными средствами, а равно на собственников транспортных средств, являющихся юридическими лицами, в размере десяти тысяч рублей.

Примечание. В случае фиксации административного правонарушения работающими в автоматическом режиме специальными техническими средствами, имеющими функции фото-и киносъемки, видеозаписи или средствами фотои киносъемки, видеозаписи и наложении на водителя транспортного средства административного штрафа одновременно дается оценка правонарушению в баллах в следующем порядке: за нарушение, предусмотренное частью второй статьи 12.5 , частями четвертой и пятой статьи 12.9 , частью первой статьи 12.10 , частью первой статьи 12.12 , частью четвертой статьи 12.15 , частью третьей статьи 12.165 баллов; статьи 12.6, частью 3 статьи 12.9, статьи 12.11, статьи 12.23, частью второй статьи 12.25 , статьи 12.36 .1 , че- 
тыре балла; частью второй статьи 12.2, частью первой статьи 12.5, частью второй статьи 12.9 , частью второй статьи 12.10 , частями первой и второй статьи 12.15 , частями четвертой, шестой и седьмой статьи 12.16, статьи 12.17 , статьи 12.21.1, статьи 12.21.2, статьи 12.21.3, статьи 12.22 три балла; частями первой, второй и третьей статьи 12.2 , частями первой и третьей прим. один статьи 12.5, частью второй статьи 12.12, статьи 12.14 , частью третьей статьи 12.15 , частями первой и второй статьи 12.16, статьями 12.18 , 12.21, частью первой статьи 12.27 два балла.

За совершение водителем транспортного средства иных правонарушений в области дорожного движения, предусмотренных главой 12 настоящего Кодекса, и зафиксированных работающими в автоматическом режиме специальными техническими средствами, имеющими функции фото-и киносъемки, видеозаписи или средствами фото- и киносъемки, видеозаписи, кроме предусмотренных частью четвертой статьи 12.2, частью 2.1 статьи 12.3, частью 1, 2, частью 3 (в случаях незаконного нанесения цветографической схемы легкового такси) статьи 12.4, частями 3,47 статьи 12.5, частью 2 статьи 12.7, статьей 12.8, частью 7 статьи 12.9 (за исключением случаев фиксации административного правонарушения работающими в автоматическом режиме специальными техническими средствами, имеющими функции фото- и киносъемки, видеозаписи), частью 3 статьи 12.10 , частью 5 статьи 12.15 (за исключением случаев фиксации административного правонарушения работающими в автоматическом режиме специальными техническими средствами, имеющими функции фото- и киносъемки, видеозаписи или средствами фото- и киносъемки, видеозаписи), частью 3.1 статьи 12.16 (за исключением случаев фиксации административного правонарушения работающими в автоматическом режиме специальными техническими средствами, имеющими функции фото- и киносъемки, видеозаписи или средствами фото- и киносъемки, видеозаписи) статьями $12.24,12.26$, частью 2 и 3 статьи 12.27 , статьей 12.35 начисляется один балл».
В целях сдерживания водителей от совершения новых правонарушений в области дорожного движения, считаем целесообразным изменить срок, предусмотренный статьей 4.6 КоАП РФ, в течение которого водители считались бы подвергнутыми административному наказанию, увеличив его от одного года до трех лет. А статью 4.1 КоАП РФ, предусматривающую общие правила назначения административного наказания, дополнить частью 4.1 следующего содержания:

«4.1. В случаях предусмотренных статьей 12.38 настоящего Кодекса, на водителя транспортного средства налагается административный штраф и одновременно дается оценка правонарушению в баллах. При этом количество набранных баллов лица, совершившего административное правонарушение в области дорожного движения, уменьшается на $1 / 3$ в случае, если оно не будет привлечено к административной ответственности за совершение нового административного правонарушения в области дорожного движения в течение одного года со дня окончания исполнения постановления по делу об административном правонарушении, на $1 / 2$ в случае, если лицо не будет привлечено к административной ответственности в течение двух лет со дня окончания исполнения постановления по делу об административном правонарушении. В случае, если лицо не будет привлечено к административной ответственности в течение трех лет со дня окончания исполнения постановления по делу об административном правонарушении количество набранных им баллов аннулируется». Причем, было бы вполне целесообразным по истечению срока лишения водительского удостоверения, водителя восстанавливать в правах на управление транспортным средством с уменьшением суммы от общего количества набранных баллов на 4 балла.

Полагаем, что реанимирование бальной системы учета правонарушений позволит реализовать принцип повышенной ответственности за повторное и систематическое нарушение Правил дорожного движения, тем самым повысить уровень безопасности дорожного движения в России.

\section{Библиография:}

1. Постановление Правительства Российской Федерации от 23 октября 1993 г. № 1090 «0 правилах дорожного движения (вместе с «Основными положениями по допуску транспортных средств к эксплуатации и обязанности должностных лиц по обеспечению безопасности дорожного движения»)» // Собрание актов Президента и Правительства РФ. 1993. № 47. Ст. 4531.

2. Кодекс Российской Федерации об административных правонарушениях от 30 декабря 2001 г. № 195 -Ф3 // Собрание законодательства РФ. 07.01.2002. № 1. Ст. 1. 
Административное и муниципальное право $11(83) \cdot 2014$

3. Driver Guide. CHAPTER $11 \neg$ THE POINT SYSTEM AND HOW IT AFFECTS YOU. SEAL OF DEPARTMENT OF REVENUE. State of MISSOURI. Revised August 2011. P. 81.

4. Десятилетие имени Федорова: Госавтоинспекция России попытка ретроспективы. // За рулем: электрон. журн. 2003. № 3. C. 18. URL: http://www.zr.ru/archive/zr/2003/03/diesiatilietiie-imieni-fiedorova. (дата обращения: 18.01.2014).

5. Федеральная целевая программа «Повышение безопасности дорожного движения в 2013 ᄀ 2020 годах»: утв. постановлением Правительства Российской Федерации от 3 октября 2013 г. № 864 // Собрание законодательства РФ. 2013. № 41. Ст. 5183.

6. Госавтоинспекция МВД России. Состояние и тенденции ДТП с водителями, находившимися в состоянии опьянения и отказавшимися от прохождения медицинского освидетельствования на состояние опьянения за 7 месяцев 2013 года. Доли правонарушений выявленных при оформлении дорожно-транспортных происшествий URL: http://www.gibdd.ru/stat/files/dtp_ns.pdf. C. $13 \neg$ Internet Explorer (дата обращения: 20.10.2014)

\section{References (transliterated):}

1. Postanovlenie Pravitel'stva Rossiiskoi Federatsii ot 23 oktyabrya 1993 g. № 1090 «0 pravilakh dorozhnogo dvizheniya (vmeste s «Osnovnymi polozheniyami po dopusku transportnykh sredstv k ekspluatatsii i obyazannosti dolzhnostnykh lits po obespecheniyu bezopasnosti dorozhnogo dvizheniya»)» // Sobranie aktov Prezidenta i Pravitel'stva RF. 1993. № 47. St. 4531.

2. Kodeks Rossiiskoi Federatsii ob administrativnykh pravonarusheniyakh ot 30 dekabrya 2001 g. № 195-FZ // Sobranie zakonodatel'stva RF. 07.01.2002. № 1. St. 1.

3. Driver Guide. CHAPTER $11 \neg$ THE POINT SYSTEM AND HOW IT AFFECTS YOU. SEAL OF DEPARTMENT OF REVENUE. State of MISSOURI. Revised August 2011. P. 81.

4. Desyatiletie imeni Fedorova: Gosavtoinspektsiya Rossii popytka retrospektivy. // Za rulem: elektron. zhurn. 2003. № 3. S. 18. URL: http://www.zr.ru/archive/zr/2003/03/diesiatilietiie-imieni-fiedorova. (data obrashcheniya: 18.01.2014).

5. Federal'naya tselevaya programma «Povyshenie bezopasnostidorozhnogo dvizheniya v $2013 \neg 2020$ godakh»: utv. postanovleniem Pravitel'stva Rossiiskoi Federatsii ot 3 oktyabrya 2013 g. № 864 // Sobranie zakonodatel'stva RF. 2013. № 41. St. 5183.

6. Gosavtoinspektsiya MVD Rossii. Sostoyanie i tendentsii DTP s voditelyami, nakhodivshimisya v sostoyanii op'yaneniya i otkazavshimisya ot prokhozhdeniya meditsinskogo osvidetel'stvovaniya na sostoyanie op'yaneniya za 7 mesyatsev 2013 goda. Doli pravonarushenii vyyavlennykh pri oformlenii dorozhno-transportnykh proisshestvii URL: http://www.gibdd. ru/stat/files/dtp_ns.pdf. S. $13 \neg$ Internet Explorer (data obrashcheniya: 20.10.2014) 